\title{
Mapa y características de los cibermedios locales e hiperlocales en España
}

\author{
Map and characteristics of local and hyperlocal digital media in \\ Spain
}

\author{
Negreira-Rey, M. C., López-García, X. y Vázquez-Herrero, J. ${ }^{1}$ \\ Recibido: 12-05-2020 - Aceptado: 10-08-2020 \\ https://doi.org/10.26441/RC19.2-2020-A11
}

RESUMEN: Durante las dos últimas décadas, el modelo mediático tradicional de la prensa local ha sufrido una profunda crisis que, unida a la económica, ha derivado en el cierre de cabeceras y recortes de personal. La creciente necesidad de una oferta informativa local veraz y la adversa realidad laboral en el sector comunicativo han motivado a muchos periodistas a fundar sus propios medios locales e hiperlocales al amparo de la red. En esta investigación se realiza un estudio exploratorio para elaborar el primer mapa de cibermedios locales e hiperlocales activos en España, con el objetivo de conocer la presencia de este tipo de medios en el Estado. Posteriormente, estos cibermedios se someten a un análisis de contenido para identificar sus características básicas y tendencias de desarrollo. Los resultados evidencian un crecimiento relevante de los cibermedios locales e hiperlocales en el país, así como unos rasgos que reflejan la búsqueda de nuevos modelos informativos desde la proximidad.

Palabras clave: medios locales; medios hiperlocales; cibermedios; ciberperiodismo; España.

\begin{abstract}
During the last two decades, the traditional media model of the local press has suffered a deep crisis which, together with the economic one, has led to the closure of many newspapers and staff cuts. The growing need for a truthful local news offer and the adverse labor reality in the communication sector have motivated many journalists to found their own local and hyperlocal media in the network. In this research, an exploratory study is carried out to elaborate the first map of local and hyperlocal online media in Spain, with the objective of knowing the presence of this type of media in the State. Subsequently, these online media are subjected to a content analysis to identify their basic characteristics and development trends. The results show a relevant growth of local and hyperlocal online media in the country, and their features reflect the search for new information models from proximity.
\end{abstract}

Keywords: local media; hyperlocal media; digital media; digital journalism; Spain.

\footnotetext{
${ }^{1}$ María-Cruz Negreira-Rey es Doctoranda en el programa de Comunicación e Información Contemporánea, Investigadora en el Grupo de investigación Novos Medios y Docente del Departamento de Ciencias de la Comunicación de la Universidade de Santiago de Compostela. cruz.negreira@usc.es, https://orcid.org/0000-0001-8945-2641

Xosé López-García es Doctor en Historia y catedrático de Periodismo, Director del Departamento de Ciencias de la Comunicación de la Universidade de Santiago de Compostela y Director del Grupo de investigación Novos Medios (Gl-1641). xose.lopez.garcia@usc.es, https://orcid.org/0000-0002-1873-8260

Jorge Vázquez-Herrero es Doctor en Comunicación e Información Contemporánea, Investigador en el Grupo de investigación Novos Medios y Docente en el Departamento de Ciencias de la Comunicación de la Universidade de Santiago de Compostela. jorge.vazquez@usc.es, https://orcid.org/0000-0002-9081-3018
} 


\section{Introducción ${ }^{2}$}

Durante las dos últimas décadas, el modelo mediático tradicional de la prensa local ha sufrido una profunda crisis (Franklin, 2006; Wadbring y Bergström, 2017), que ha derivado en el cese de cabeceras, recortes de personal, cierre de delegaciones y pérdida de cobertura periodística en los ámbitos más cercanos a los ciudadanos. Esta situación, observada a nivel internacional, ha dejado sin información local grandes áreas geográficas, originando los denominados desiertos mediáticos (Bucay, Elliot, Kamin y Park, 2017; Ferrier, Sinha y Outrich, 2016). La carencia de un mediador informativo entre los órganos de poder y los ciudadanos ha despertado la preocupación por el déficit de la función democrática que los medios de proximidad ejercen en las comunidades locales (Ahva y Wiard, 2018; Barnett y Townend, 2015; (Chen et al., 2017); Harcup, 2016).

Aunque los medios locales son uno de los sectores más vulnerables a las recesiones económicas, siguen constituyendo la principal fuente de noticias para los ciudadanos de la mayoría de países. Esta confianza se refleja en una suscripción cada vez más frecuente de los usuarios a títulos de prensa local (Newman, Fletcher, Schulz, Andi y Kleis, 2020).

En un contexto de crisis, las cabeceras locales han tenido que afrontar su transición al modelo digital, cada vez más móvil y multiplataforma, haciendo frente a un mercado reducido y a unas estructuras empresariales cada vez más limitadas (Jenkins y Kleis Nielsen, 2018). Esto supuso, en muchos casos, la búsqueda del equilibrio entre un modelo impreso que aún es rentable en el escenario local y la experimentación y diversificación de vías de ingresos en lo digital (Jenkins y Kleis Nielsen, 2020).

Paralelamente, durante los últimos años se ha observado una renovación mediática en los ámbitos de proximidad con el lanzamiento de múltiples cibermedios locales e hiperlocales. Este fenómeno, observado a nivel internacional, se vio favorecido por el bajo coste para la producción y distribución de contenido en la red, la creciente demanda de información local o el cambio de comportamiento de las audiencias hacia roles más activos (Radcliffe, 2015). Este tipo de proyectos buscan, por lo común, ocupar el hueco informativo olvidado por los grandes medios tradicionales, ofrecer una alternativa que visibilice el área geográfica local e hiperlocal y dé voz a sus vecinos, así como desarrollar una función social (Harte, Turner y Williams, 2016; Tenor, 2019).

El auge del emergente modelo de los medios hiperlocales ha sido estudiado por investigadores de diversos países. Así, estos cibermedios ya han sido mapeados en Estados Unidos (Horning, 2012), Reino Unido (Harte, 2013), Países Bajos (Kerkhoven y Bakker, 2014), Suecia (Nygren, Leckner y Tenor, 2018), Finlandia (Hujanen, Lehtisaari, Lindén y Grönlund, 2019) o Noruega (Halvorsen y Bjerke, 2019). Cada vez más numerosos en el panorama mediático internacional, los medios hiperlocales buscan, por lo general, llenar los huecos olvidados por los medios tradicionales (Metzgar, Kurpius y Rowley, 2011) y ofrecer una visión alternativa de lo que ocurre en la comunidad (Harte, Williams y Turner, 2016). Es por ello que se caracterizan por su orientación comunitaria (Radcliffe, 2015) y por una oferta informativa que pretende responder a los temas de interés para el día a día de los vecinos (D’Heer y Paulussen, 2013; Kerkhoven y Bakker, 2014; Williams, Harte y Turner, 2015). A nivel organizativo, se trata de proyectos impulsados por periodistas independientes o equipos poco numerosos que pueden integrar la participación de las audiencias en el proceso productivo en forma de colaboraciones más o menos regulares (Radcliffe, 2015).

En el contexto español, donde los medios regionales y locales han ocupado un lugar significativo

\footnotetext{
2 Este artículo se ha elaborado en el marco del proyecto "Cibermedios nativos digitales en España: formatos narrativos y estrategia móvil” (Referencia RTI2018-093346-B-C33), del Ministerio de Ciencia, Innovación y Universidades, cofinanciado por el Fondo Europeo de Desarrollo Regional (FEDER).
} 
desde la transición democrática, también se ha observado una renovación mediática en los ámbitos de proximidad durante las últimas dos décadas. La crisis del modelo tradicional, unida a la económica, dejó sin empleo a más de 12.000 profesionales. Ante esta situación, fueron muchos los que optaron por crear sus propios proyectos informativos, en su mayoría nativos digitales (APM, 2015; 2019). Según la Asociación de la Prensa de Madrid (2015; 2019), los periodistas españoles fundaron hasta 579 cibermedios entre 2008 y 2015 -permaneciendo activas en 2019 un total de 302 cabeceras-, siendo mayoritarios los medios de carácter local (APM, 2017).

Se comenzó a experimentar, de este modo, una fase de crecimiento del ciberperiodismo de proximidad y de los nuevos medios hiperlocales, que ha permitido a los ciudadanos seguir disponiendo de información actualizada sobre lo que ocurre en su entorno más inmediato (González Esteban, 2012a). Entre los proyectos informativos desarrollados en estos años conviven tanto medios nativos digitales, como aquellos que optan por mantener el papel al mismo tiempo que optimizan sus ediciones web e incorporan al usuario como actor activo (González Esteban, 2009).

Este proceso de continua transformación que experimenta el ecosistema de los cibermedios locales e hiperlocales en España requiere de su estudio en profundidad desde el ámbito académico. A la hora de abordar este objeto de estudio a nivel estatal, falta una base de datos o mapa actualizado de los mismos que sirva como punto de partida. En los últimos años se han desarrollado algunos mapeos de medios locales en distintas comunidades autónomas, pero no con una vocación exhaustiva para toda España ni poniendo el foco en los cibermedios.

Desde la academia, se han desarrollado el Mapa de radios públicas locales de Andalucía (COMandalucía, 2019a), el Mapa de radios comunitarias y ciudadanas de Andalucía (COMandalucía, 2017), el Mapa de televisiones públicas locales de Andalucía (COMandalucía, 2013), el Mapa de radios municipales de Murcia (COMandalucía, 2019b), el Mapa de medios de Cataluña (LPCCP, 2008) -que identifica comarca a comarca la totalidad de los medios de la comunidad-, Mediamapa. gal (Negreira-Rey, 2017) -que registra los medios en activo en Galicia-, o los mapeos por comarcas de la provincia de Alicante realizados por el grupo GICOV en sus Cuadernos Comarcales (González, 2012b).

Es también destacable la labor de algunas asociaciones de medios locales que, además de servir de apoyo a las cabeceras asociadas, ofrecen un mapeo de las mismas. Algunas de ellas son la Associació Catalana de la Premsa Comarcal (ACPC, 2020), la también catalana Associació de Mitjans d'Informació i Comunicació (AMIC, 2020), la vasca Tokikom (2020), la Asociación de Medios en Galego (2020) de Galicia o la Asociación de Emisoras Municipales y Ciudadanas de Andalucía de Radio y Televisión (EMA-RTV, 2020).

Por todo ello, se hace evidente la necesidad de elaborar un instrumento que permita abordar el estudio en profundidad de los cibermedios locales e hiperlocales en España. El presente trabajo parte del planteamiento de las siguientes preguntas de investigación:

PI1. ¿Cuál es el mapa actual de los cibermedios locales e hiperlocales en España? ¿Se observa un crecimiento de este tipo de medios?

PI2. ¿Cómo son estos cibermedios? ¿Sus características y tendencias de desarrollo indican una renovación mediática en los ámbitos de proximidad?

\section{Marco teórico}

En el contexto de la aldea global (McLuhan y Powers, 1992), lo 'glocal' (López García, 2008) integra en una misma realidad el lugar físico y cultural local y el espacio mediado de la red global. 
La 'glocalización' aúna, en una misma realidad, la homogeneización global de las sociedades -y de su oferta informativa - y el interés creciente por parte de los ciudadanos por la información cercana (Esteve Ramírez, 2012). El territorio físico mantiene su vinculación con las dimensiones sociales, culturales y naturales de cada lugar para crear el 'ser local' (Hess y Waller, 2016), de forma que lo local continúa siendo un generador de significado periodístico ligado a la comunidad (Schmitz Weiss, 2015; 2020).

A pesar de que la comunidad local no puede ser entendida como una entidad independiente limitada por las fronteras locales (Kleis Nielsen, 2015), sigue siendo el foco sobre el que trabajan los medios de proximidad y sus periodistas (Camponez, 2002). Es aquí donde los medios locales desarrollan no solo una misión informativa, sino también social (Martínez Juan, 2003; Richards, 2013). Firmstone (2016) actualiza los roles que desempeñan los medios locales, señalando su labor informativa -que busca el equilibrio entre el interés público de las noticias y la implicación de la audiencia con lo que ocurre en el gobierno local-, su rol social activo -que pueden asumir en el impulso y apoyo de campañas sociales- y su función democrática -al visibilizar y representar múltiples puntos de vista, ser vigías del poder e integrar el contenido producido por los ciudadanos-.

El valor de lo local, el interés que genera en la comunidad y la renovación de las funciones de los medios de proximidad nos sitúan en un contexto de transformación de los modelos informativos de los medios locales e hiperlocales en la red.

\subsection{Transformación de los medios de proximidad en España}

El mapa actual de los cibermedios locales e hiperlocales españoles responde a una serie de transformaciones mediáticas, políticas y sociales sufridas durante las últimas décadas. Entender la situación actual requiere contextualizar este proceso y repasar la evolución reciente de los medios de proximidad en el país.

Fue en los años ochenta, tras el fin de la dictadura y la aprobación de la Constitución en 1978, cuando la supresión de la Prensa del Movimiento permitió el resurgir de la prensa regional y local (Guillamet, 2002). Se inició entonces un proceso de potenciación de la comunicación de proximidad debida, según Macià Mercadé (1993), a una transición política que excitó la opinión pública y favoreció el protagonismo mediático, la configuración político-administrativa de España como un Estado de Autonomías, la privatización de los medios, la concesión de canales privados de televisión y ampliación de emisoras radiofónicas, así como la irrupción acelerada de las nuevas tecnologías de la información.

En la prensa se observaron dos tendencias de crecimiento: la creación de grandes grupos editoriales como Prensa Ibérica, Grupo Moll o Grupo Correo, y la regionalización de las grandes cabeceras centrales y nacionales (Guillamet, 2002). Esto se tradujo en un aumento del número de diarios regionales y locales -se pasó de 29 cabeceras en 1972 a 56 en 1999 (Guillamet, 2002)-, que llegaron a liderar la difusión en quince de las diecisiete comunidades autónomas, obteniendo un 39\% más de lectores que la prensa nacional (Fontcuberta, 1997).

Además del desarrollo de la prensa, durante la década de los ochenta empezaron a proliferar los medios radiofónicos y audiovisuales de proximidad, cuyo crecimiento regulado no se alcanzó hasta los años noventa, con la aprobación en 1991 de la Ley de Organización y Control de las Emisoras Municipales de Radiodifusión Sonora y en 1995 de la Ley de Televisión Local por Ondas Terrestres (López García y Macià Mercadé, 2007). Esto provocó que entre los años 1995 y 2002 se creasen más emisoras que durante los primeros 14 años de su existencia, llegando a un censo en la AIMC de 897 televisiones locales en el 2002 (Badillo Matos, 2005). 
Durante los setenta y los ochenta también comenzó a crecer la prensa de barrio, que se puede entender como el antecedente de los actuales cibermedios hiperlocales. Los primeros títulos surgieron en la década de los sesenta como una respuesta informativa local a los esquemas vigentes de los grandes grupos de comunicación convencionales. Fueron promovidos por asociaciones y entidades vecinales para demostrar que una prensa alternativa y próxima era posible (López García y Macià Mercadé, 2007). En 1993 se contaban en Madrid hasta 20 publicaciones de barrio -entre las que destacaban el quincenal Chamartín o el semanal Barrio de Salamanca-, mientras que en Sevilla se identificaban hasta 17 cabeceras en el año 2002 (López García y Macià Mercadé, 2007).

Viendo el interés que generaban este tipo de publicaciones, muchos ayuntamientos decidieron lanzar sus propios boletines, en muchos casos con un tono propagandístico (López García y Macià Mercadé, 2007). De este modo, en 1986 eran 33 los ayuntamientos de capital de provincia que editaban un periódico, la mayoría con una periodicidad mensual.

La década de los ochenta fue también la del crecimiento de los medios comunitarios (Lauterer, 2006). Como iniciativas vecinales locales nacieron las primeras televisiones comunitarias, de las cuales doce - RTV Cardedeu, Canal Palamós, TV Vilassar, Anoia TV, TV Centelles, TV Vilanova, Tele Horta, Tele Aspe, Tele K, Canal 33, Televisión Fregenal y Telemolina- pudieron seguir emitiendo en digital después de la aprobación de la Ley de Medidas de Impulso de la Sociedad de la Información del 2007 (Fleischman y Sáez, 2009).

Durante los noventa también se produjo una paulatina institucionalización de los medios comunitarios. Así, la prensa de barrio pasó a manos de nuevos promotores-como empresas o asociaciones de comerciantes-, la radio evidenció la necesidad de ejecutar proyectos políticos y el movimiento del cine fue absorbido por las instituciones. Con la creación de la Red de Medios Comunitarios en 2005, estos consiguieron tener una unidad organizativa y representativa (Fleischman, Reguero y Sáez, 2009).

El crecimiento de los medios de proximidad en España en estos años lo refleja Macià Mercadé (1993) en un mapa elaborado en 1990. En él registra 95 periódicos regionales o locales, 427 emisoras locales de radio y 113 televisiones locales.

Al final de los noventa, la prensa regional y local ocupa aún una posición dominante en el mercado español, con importantes lanzamientos editoriales, alianzas y movimientos empresariales entre los principales grupos de comunicación (Egea Santiago, 2002). En un contexto altamente competitivo, las cabeceras cambian sus prioridades informativas y afrontan su adaptación al escenario digital y multimediático (López, 1999). Con la llegada de los 2000, el número de cabeceras locales se mantiene estable (López García y Macià Mercadé, 2007) y los grupos Vocento, Prensa Ibérica, Grupo Zeta y Grupo Voz consiguen proteger su posicionamiento en el mercado durante la primera década del nuevo milenio (Izquierdo Labella, 2010).

Los inicios del ciberperiodismo en España a partir de 1995 pronto impulsaron las primeras experiencias de medios de proximidad en la red. Así, El Correo Gallego lanza ya en 1995 una edición digital (López-García y Negreira-Rey, 2016), al que se suman el Diario Vasco (Salaverría, Cores, Díaz, Meso y Larrondo, 2004) y Barcelona Televisió, la primera televisión local con presencia en Internet (Pérez Dasilva y Santos Díez, 2009). Pronto aparecen también los primeros nativos digitales, como el catalán Vilaweb en 1996 (García Avilés y González Esteban, 2012) o la televisión local Proyección TV, creada en el 2000 (Pérez y Santos, 2009).

El desarrollo de los cibermedios locales en España fue parejo al del ciberperiodismo de las cabeceras nacionales y generalistas del Estado -sumando en 2005 un total de 1.274 cibermedios de todo 
tipo en el país (Salaverría, 2008)-, quedando plasmadas sus particularidades en algunas de las investigaciones territoriales realizadas en estos años.

Uno de los primeros estudios fue el llevado a cabo por Díaz Noci y Meso Ayerdi (1998) en el País Vasco. En él reflejaron unos cibermedios en los que predominaba la replicación de textos de las cabeceras matriciales, sin una estrategia propia de producción y difusión de contenidos. Sobre la realidad vasca y navarra, Salaverría et al. (2004) señalaron una presencia tardía de los medios de proximidad en la red y un nivel todavía bajo en la explotación de la interactividad y el modelo multimedia. También en el contexto vasco, Díaz Noci (2005) localiza en el 2005 un total de 186 cibermedios activos.

En la Comunidad Valenciana destacan los censos de cibermedios realizados por López García (2012), en los que llega a identificar un total de 465 en 2011. En Cataluña, Masip (2008) señala una revitalización del ciberperiodismo de proximidad a partir del 2007, destacando además el modelo multimedia de algunos grupos de comunicación locales (Masip et al., 2011). En Galicia también se constata una renovación a partir del año 2010, cuando todos los diarios de información general cuentan con una edición online que experimenta con las vías para la participación de la audiencia, los elementos multimedia y la renovación de sus diseños (López García, 2012).

En este contexto, en el que los grupos hegemónicos intentan adaptar su estrategia editorial al escenario online y optimizar sus cibermedios, la crisis del propio modelo tradicional y la recesión económica sufrida a partir de 2008 aceleran un proceso de cambio y renovación mediática en los ámbitos de proximidad. Es en los años 2008 y 2009 cuando surgen los primeros cibermedios hiperlocales en España -entre ellos, cabeceras como A Voces de Carabanchel, Hortaleza en Red, OMC Radio Villaverde, o Zona Retiro-, casi todos ellos creados por periodistas independientes (Flores Vivar, 2014). El interés por la información cada vez más cercana al ciudadano y el paulatino crecimiento de este tipo de iniciativas hizo que algunos grupos como Vocento experimentasen con ediciones hiperlocales, en este caso creadas a partir del diario extremeño Hoy (Izquierdo Labella, 2012).

El auge de un nuevo modelo de cibermedios locales e hiperlocales en España fue observado por la Asociación de la Prensa de Madrid, que llegó a censar 579 proyectos lanzados por periodistas entre los años 2008 y 2015, de los cuales 124 eran cibermedios de carácter autonómico, local e hiperlocal (APM, 2015). En un estudio posterior en el que se analizaron las iniciativas de cibermedios locales nativos digitales (APM, 2017) se concluyó lo siguiente: la mayor parte de estos medios fueron fundados a partir del 2011, como consecuencia de la crisis económica; más de la mitad se constituyen como sociedades limitadas, siendo también frecuentes las civiles, anónimas y cooperativas; son cibermedios que suelen establecer relaciones colaborativas con otros proyectos locales; tienen la web como plataforma principal, manteniendo algunos edición en papel -habitualmente gratuita- y estando presentes mayoritariamente en las redes sociales; se trata de proyectos empresariales que difícilmente alcanzan la rentabilidad económica -el $61 \%$ afirma tener unos ingresos por debajo de los 100.000 euros-, por lo que diversifican sus fuentes de ingresos; $y$, en su mayoría, tienen un equipo profesional muy reducido -el $56 \%$ cuenta con menos de cuatro trabajadores-.

En esta última década se observa, por tanto, un período de alta inestabilidad y renovación mediática en los ámbitos de proximidad. El escenario dominado por los buenos resultados de los grandes grupos de la prensa regional y local a comienzos del milenio se ha transformado en otro en el que la crisis del modelo tradicional ha dejado hueco a nuevos proyectos de cibermedios locales e hiperlocales que, a pesar de unas condiciones precarias e inciertas, exploran nuevas formas de hacer periodismo de proximidad de manera sostenible. 


\subsection{Conceptualización de los cibermedios locales e hiperlocales en el contexto español}

Elaborar y analizar el mapa actual de los cibermedios locales e hiperlocales en España requiere delimitar su conceptualización, a fin de poder discriminar los medios que deben ser incluidos en dicho mapeo. Esta es una cuestión compleja debido a los factores que se interrelacionan a la hora de definir un medio por su alcance o vinculación con el territorio, a menudo dependientes del contexto en el que se plantea.

Para ello es necesario partir de las aportaciones realizadas por otros autores hasta el momento, adaptando las propuestas lanzadas desde el ámbito internacional a los estudios y clasificaciones sobre la realidad española. Aunque esta adaptación conceptual ya ha sido abordada en una investigación anterior (Negreira-Rey, López-García y Rodríguez-Vázquez, 2018), a continuación se resumen los conceptos tratados para la delimitación teórica de los cibermedios locales e hiperlocales en España.

En la definición de lo local se han tratado y contrapuesto diversos conceptos por parte de los investigadores españoles. Del término mesocomunicación -propuesto por Moragas (2015) en los ochentase pasó a finales de los noventa a la denominación de periodismo o medios de proximidad -justificada por su flexibilidad para referirse a medios de diverso alcance (Moragas, Garitaonandía y López, 1999), por su alusión a la creación de una relación cercana con la audiencia en un mismo mundo referencial (Fastrez y Meyer, 1999), o empleada como concepto que engloba desde los medios locales hasta los regionales (López García, 2008)-, o a la de información cercana (Ruiz del Árbol, 1986).

Con todo, se mantuvo vigente el término de periodismo local, asociado al factor geográfico (De la Mota, 1988), al tipo de contenido (López de Zuazo, 1976), o interrelacionando ambas dimensiones con el factor social y cultural (Cantalapiedra, 1997; Esteve Ramírez, 2002; Guillamet, 1983; Izquierdo Labella, 2010). La conceptualización de la comunicación local conjuga, por lo tanto, "una mediación técnica a través del sistema mediático actual en un lugar físico (en un territorio) o virtual (en una comunidad de usuarios de una cultura, valores o intereses relacionados con una localidad)" (Lopez García, 2004, p. 29).

En esta investigación, la delimitación de la dimensión local de los medios en el contexto español se fundamenta en la definición de los espacios de comunicación propuesta por López García (2004), que parte de los niveles propios de la organización territorial y administrativa del Estado-Nación. De este modo, se identifica el espacio local con los municipios y las comarcas -incluyendo como niveles intermedios el intermunicipal e intercomarcal-, el regional con las regiones, el nacional con el Estado y el internacional con varios estados (López García, 2004).

La delimitación del espacio hiperlocal debe fundamentarse en las propuestas aportadas desde el panorama internacional, pues su concepción territorial aún no ha sido abordada en el contexto español con anterioridad. Para ello se parte de una de las definiciones de referencia de los medios hiperlocales basada en el factor geográfico, que es la propuesta por Radcliffe (2012). El autor delimita el alcance informativo de los hiperlocales a una ciudad, un pueblo, un código postal o a cualquier otra comunidad pequeña definida geográficamente. Trasladando esta idea a la realidad española, y teniendo en cuenta que el nivel local abarca hasta el municipio, se pueden definir como áreas propias del hiperlocal aquellas que están por debajo del municipio, que serían el barrio, la parroquia o el distrito.

Para la definición de cibermedio se sigue la propuesta de López García et al. (2005, p. 40), quienes lo describen como "aquel emisor de contenidos que tiene voluntad de mediación entre hechos y público, emplea fundamentalmente criterios y técnicas periodísticas, usa el lenguaje multimedia, es interactivo e hipertextual, se actualiza y se publica en la red Internet". 
Se concluye, por lo tanto, que en el contexto español se tratan como cibermedios locales aquellos que tienen como área de cobertura informativa el municipio o la comarca, integrando del mismo modo los niveles intermunicipal e intercomarcal. Por otro lado, se consideran hiperlocales los que cubren informativamente un espacio más pequeño que el municipio, como pueden ser el distrito, el barrio o la parroquia -y la agrupación de los mismos-.

\section{Metodología}

El objetivo principal de este trabajo es contribuir a la elaboración y actualización periódica del primer mapa de cibermedios locales e hiperlocales en España, que permita explorar la realidad estatal a partir de datos sistematizados y fiables. De forma específica, se busca identificar las principales características básicas y tendencias de desarrollo de estos cibermedios, a fin de comprobar si se está produciendo o no una renovación mediática en los ámbitos de proximidad.

La primera fase de la investigación es un estudio exploratorio (Dahnke, 1986) en el que se busca localizar e identificar el conjunto de los cibermedios locales e hiperlocales del Estado. Esta exploración se enmarca en las acciones del proyecto coordinado de $\mathrm{I}+\mathrm{D}+\mathrm{i}$ "Usos y preferencias informativas en el nuevo mapa de medios en España" (2016-2018) (Referencia: CSO2015-64662C4-1-R) ${ }^{3}$, dirigido por María del Pilar Martínez-Costa y financiado por el Ministerio de Economía y Competitividad y por el Fondo Europeo de Desarrollo Regional, en el que se ha actualizado el mapa de los cibermedios en España y cuyos resultados generales han sido publicados con anterioridad (Salaverría, Martínez-Costa y Breiner, 2018).

La identificación de los cibermedios locales e hiperlocales españoles tomó como punto de partida la revisión de diversas fuentes documentales, entre las que se incluyen agendas oficiales de comunicación, informes o directorios de diversas asociaciones periodísticas de las distintas comunidades autónomas. Los datos obtenidos se complementan, posteriormente, con una búsqueda sistematizada en Google para la que se emplean diversas ecuaciones: noticias OR medio AND localidad; diario OR diario digital AND localidad; periódico AND localidad; radio AND localidad; televisión AND localidad. En el lugar de la palabra clave 'localidad' se introducen los topónimos de los municipios más poblados de cada provincia -aquellos con más de 20.000 habitantes según los datos del Instituto Nacional de Estadística-.

Esta primera fase exploratoria permite construir una base de datos de los cibermedios locales e hiperlocales españoles, que se restringe a los medios activos -que registran alguna publicación en los cinco meses anteriores a su integración en el mapa (Harte, 2013)-, de temática generalista -que tratan una gama variada de asuntos y aspiran a cubrir toda la información actual relevante para el público (Salaverría, 2017) - y enfoque periodístico - se excluyen los que atienden intereses que no son estrictamente informativos (Salaverría, 2017)-.

En una segunda fase de la investigación, de tipo descriptivo (Berganza y Ruiz, 2005), los cibermedios locales e hiperlocales mapeados son sometidos a un análisis de contenido de carácter cuantitativo (Berelson, 1952; Krippendorf, 1980) para conocer sus características básicas. El instrumento empleado es una ficha, cuyas categorías y variables se indican en la Tabla 1, elaborada en base a la última actualización de la clasificación de los cibermedios propuesta por Salaverría (2017).

\footnotetext{
${ }^{3}$ Los autores de este trabajo han participado desde el subproyecto "Usos y preferencias informativas en el nuevo mapa de medios en España: modelos de periodismo para dispositivos móviles" (Referencia: CSO2015-64662-C44-R), dirigido por Xosé López García y financiado por el Ministerio de Economía y Competitividad y por el Fondo Europeo de Desarrollo Regional.
} 
Tabla 1. Ficha de análisis aplicada a los cibermedios locales e hiperlocales.

\begin{tabular}{|l|l|}
\hline Datos identificativos & $\begin{array}{l}\text { Nombre del cibermedio; URL; correo / teléfono de } \\
\text { contacto; constitución legal; domicilio social. }\end{array}$ \\
\hline Plataforma & Web; papel; radio; televisión; app móvil. \\
\hline Nativo digital & Sí; no. \\
\hline Temporalidad & Periódica; de actualización continua; multitemporal. \\
\hline $\begin{array}{l}\text { Alcance geográfico (categorizado en base a los } \\
\text { conceptos y criterios expuestos en el marco teórico) }\end{array}$ & $\begin{array}{l}\text { Local (municipal, intermunicipal, comarcal, } \\
\text { intercomarcal); hiperlocal (barrio, distrito). }\end{array}$ \\
\hline Titularidad & Pública; privada. \\
\hline Idioma & $\begin{array}{l}\text { Se contemplan los idiomas nacionales y/o } \\
\text { extranjeros en los que se editan los cibermedios. }\end{array}$ \\
\hline
\end{tabular}

Fuente: elaboración propia.

Los resultados que se presentan en este trabajo son los de la última actualización del mapa y revisión del análisis de los cibermedios mapeados, finalizada en agosto de 2018.

Aunque el mapa que se presenta en este artículo actualiza el conocimiento sobre los medios de proximidad en España, no está exento de limitaciones. El alto número de iniciativas de información local e hiperlocal que surgen en la red, su reducido alcance, la falta de censos y agendas que incluyan este tipo de medios o la alta inestabilidad del sector hace que sea complejo mapear la totalidad de estas cabeceras de manera exhaustiva. Los resultados que se exponen a continuación deben comprenderse, por lo tanto, como una aproximación al universo de los cibermedios locales e hiperlocales españoles, cuyos datos deberán seguir siendo actualizados en el futuro.

\section{Resultados}

El mapeo de los cibermedios locales e hiperlocales activos en España, de temática generalista y enfoque periodístico, ha resultado en la identificación de un total de 1.210 cabeceras. En el mapa se catalogan 1.148 cibermedios locales -con un alcance municipal $(n=701)$, intermunicipal $(n=142)$, comarcal $(\mathrm{n}=261)$ e intercomarcal $(\mathrm{n}=44)$ - y 62 cibermedios hiperlocales - con un alcance de barrio o distrito-.

Figura 1. Mapa de los cibermedios locales e hiperlocales en España.
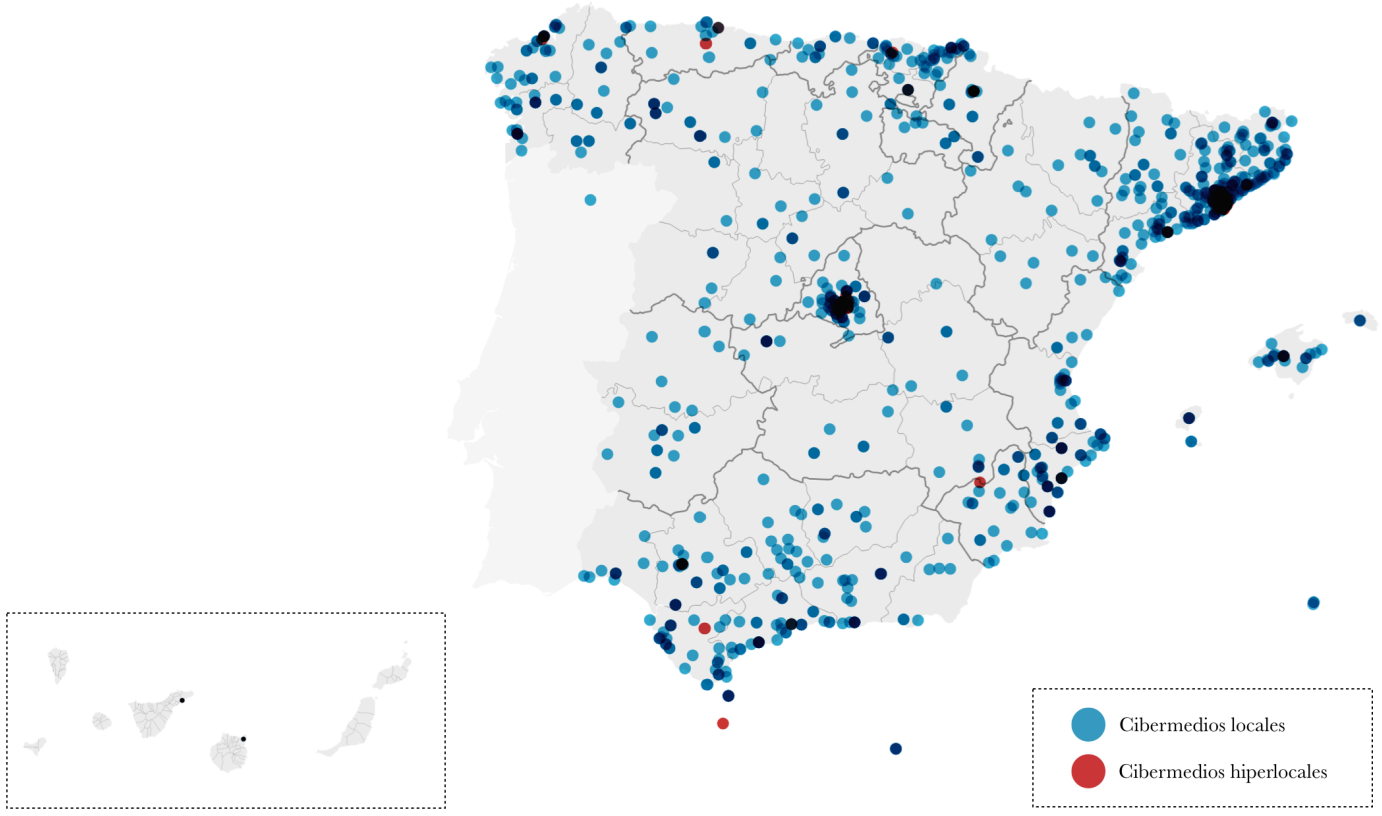

Fuente: elaboración propia. 


\subsection{Distribución geográfica de los cibermedios locales e hiperlocales}

La distribución territorial de los cibermedios locales e hiperlocales mapeados no es homogénea para todo el Estado. Estos tienden a concentrarse en aquellas comunidades autónomas y provincias más pobladas, con una mayor actividad económica y social, y también con un mayor número de medios de comunicación.

Tabla 2. Número de cibermedios locales e hiperlocales por Comunidad Autónoma.

\begin{tabular}{|c|c|c|c|}
\hline Comunidad Autónoma & $\begin{array}{l}\text { Cibermedios } \\
\text { locales }\end{array}$ & $\begin{array}{l}\text { Cibermedios } \\
\text { hiperlocales }\end{array}$ & $\begin{array}{c}\text { Total } \\
\text { general }\end{array}$ \\
\hline Andalucía & 186 & 5 & 191 \\
\hline Aragón & 22 & 0 & 22 \\
\hline Canarias & 47 & 0 & 47 \\
\hline Cantabria & 18 & 0 & 18 \\
\hline Castilla y León & 53 & 1 & 54 \\
\hline Castilla-La Mancha & 37 & 0 & 37 \\
\hline Cataluña & 310 & 24 & 334 \\
\hline Ceuta & 7 & 0 & 7 \\
\hline Comunidad de Madrid & 91 & 20 & 111 \\
\hline Comunidad Foral de Navarra & 20 & 3 & 23 \\
\hline Comunidad Valenciana & 95 & 1 & 96 \\
\hline Extremadura & 23 & 0 & 23 \\
\hline Galicia & 85 & 2 & 87 \\
\hline Islas Baleares & 38 & 0 & 38 \\
\hline La Rioja & 9 & 0 & 9 \\
\hline Melilla & 4 & 0 & 4 \\
\hline País Vasco & 57 & 2 & 59 \\
\hline Principado de Asturias & 14 & 2 & 16 \\
\hline Región de Murcia & 32 & 2 & 34 \\
\hline Total general & 1148 & 62 & 1210 \\
\hline
\end{tabular}

Fuente: elaboración propia.

Como se observa en la Tabla 2, las comunidades autónomas con una mayor presencia de cibermedios locales son Cataluña, Andalucía, la Comunidad Valenciana, la Comunidad de Madrid, Galicia, el País Vasco y Castilla y León, todas ellas con más de 50 medios de este tipo. En cuanto a los cibermedios hiperlocales, estos se concentran en su mayoría en Cataluña y Madrid. Ambas comunidades son las que presentan, en general, una mayor concentración mediática, siendo además Cataluña la que posee una red de cabeceras locales más densa y Madrid la capital donde se crearon los primeros hiperlocales.

Las comunidades autónomas con una mayor densidad de cibermedios locales e hiperlocales son también las que concentran un mayor número de cibermedios de todo tipo (Salaverría, Martínez-Costa y Breiner, 2018). Este patrón se mantiene desde el primer mapa de cibermedios realizado en España en el año 2005 (Pereira et al., 2005), cuando las comunidades con más medios en la red eran la Comunidad de Madrid, Cataluña, Andalucía, el País Vasco, Galicia, la Comunidad Valenciana y Castilla-La Mancha.

\subsection{Características de los cibermedios locales e hiperlocales españoles}

Los cibermedios locales e hiperlocales incluidos en el mapa han sido sometidos a un análisis de contenido para identificar sus características básicas. A continuación se detalla la dimensión mul- 
tiplataforma de estos medios, la incidencia de los nativos digitales, la temporalidad en cuanto a la actualización de los cibermedios, la titularidad público o privada de las organizaciones mediáticas y el idioma empleado para la edición y publicación de los contenidos.

\subsubsection{Plataformas}

Todos los medios analizados tienen, por su condición de cibermedios, presencia en la web. Pero además, como se detalla a continuación, es frecuente que en su estrategia editorial combinen la edición web con la de otras plataformas -entendidas como la tecnología digital que posibilita cierto tipo de publicación-.

En la Tabla 3 se resumen estos datos, indicando el número de cibermedios locales e hiperlocales con edición impresa, canal de televisión, emisora radiofónica y aplicación móvil, señalando también su porcentaje sobre el total de cada tipo de medio. Se contabilizan como ND aquellos casos en los que no fue posible comprobar la presencia o ausencia de los cibermedios en las distintas plataformas.

Tabla 3. Cibermedios locales e hiperlocales clasificados por plataforma.

\begin{tabular}{|l|c|c|r|r|r|}
\multicolumn{2}{|c|}{ Plataforma } & \multicolumn{2}{c|}{ Cibermedios locales } & \multicolumn{2}{c|}{ Cibermedios hiperlocales } \\
\cline { 2 - 6 } & $n$ & $\%$ & $n$ & $\%$ \\
\hline \multirow{3}{*}{ Papel } & $\checkmark$ & 221 & $19,3 \%$ & 20 & $32,3 \%$ \\
\cline { 2 - 6 } & ND & 70 & - & 2 & - \\
\hline \multirow{2}{*}{ TV } & $\checkmark$ & 116 & $10,1 \%$ & 2 & $3,2 \%$ \\
\cline { 2 - 6 } & ND & 69 & - & 1 & - \\
\hline \multirow{2}{*}{ Radio } & $\checkmark$ & 452 & $39,4 \%$ & 13 & $20,9 \%$ \\
\cline { 2 - 6 } & ND & 68 & - & 1 & - \\
\hline \multirow{2}{*}{ App } & $\checkmark$ & 203 & $17,7 \%$ & 2 & $3,2 \%$ \\
\cline { 2 - 6 } & ND & 0 & - & 0 & - \\
\hline
\end{tabular}

Fuente: elaboración propia.

De forma general para ambos tipos de cibermedios, la radio y el papel son las plataformas complementarias a la web más frecuentes, siendo la primera la más común entre los locales $(39,4 \%)$ y la segunda la más repetida entre los hiperlocales $(32,3 \%)$. La preponderancia de estas se corresponde con una mayor presencia de periódicos impresos y emisoras radiofónicas como medios matriz de los cibermedios analizados.

Por otro lado, la menor incidencia de televisiones en los ámbitos comunicativos de proximidad hace que esta solo sea una plataforma activa para el 10,1\% de los cibermedios locales y para el 3,2\% de los hiperlocales. En cuanto a la extensión al medio móvil, se evidencia que esta es aún minoritaria, pues solo un $17,7 \%$ de cibermedios locales ofrece una app para el consumo de sus contenidos en el smartphone y solo un 3,2\% de los hiperlocales disponen de aplicación móvil.

En cuanto al carácter multiplataforma de los cibermedios estudiados, tal y como se observa en la Figura 2, este es mayoritario.

El número de cibermedios locales e hiperlocales que están presentes en al menos dos plataformas -529 y 33 , respectivamente-, supera a los que solo poseen edición web -393 locales y 27 hiperlocales-. En total, un $65,7 \%$ de los cibermedios locales tienen ediciones multiplataforma, frente al $56,4 \%$ de hiperlocales. Aun así, son minoritarios los casos de cibermedios locales e hiperlocales que mantienen tres plataformas activas -el $18,7 \%$ y el 3,2\%, respectivamente- y excepcionales los cibermedios que mantienen hasta cuatro -el $0,9 \%$ de los locales y ningún hiperlocal-. 
Figura 2. Cibermedios locales e hiperlocales por número de plataformas.

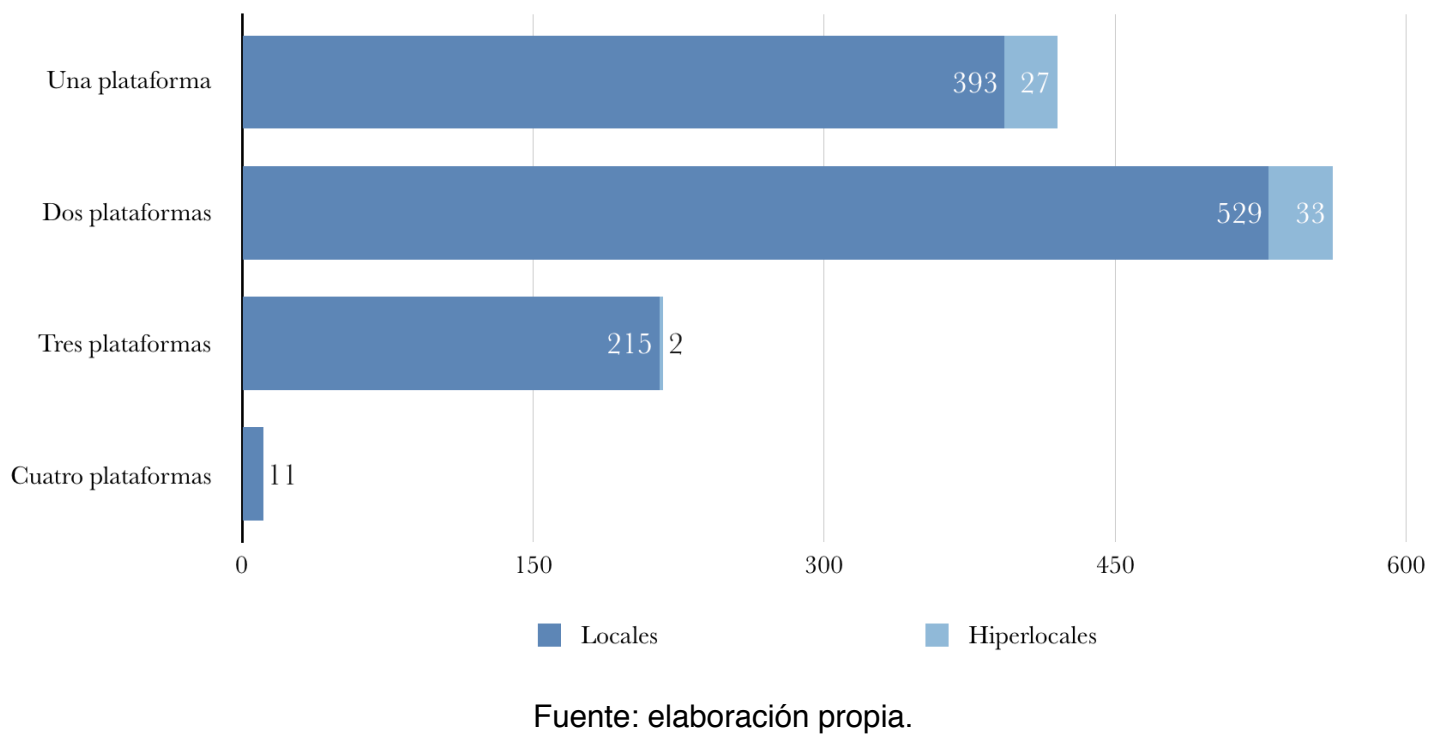

\subsubsection{Nativos digitales}

Como ya se ha detallado, son mayoritarios los cibermedios locales e hiperlocales que, además de la web, disponen de una plataforma matriz como la edición impresa o la radio. En consonancia, también se observa que la mayoría de los medios analizados no son nativos digitales -esto es, medios que solo existen en Internet y cuyo principal canal de distribución es la red-. De este modo, como refleja la Figura 3, tan solo 358 cibermedios locales -el 31,2\% del total de estos medios- y 26 cabeceras hiperlocales -el 40,6\%- son nativos digitales.

Figura 3. Cibermedios locales e hiperlocales nativos digitales.
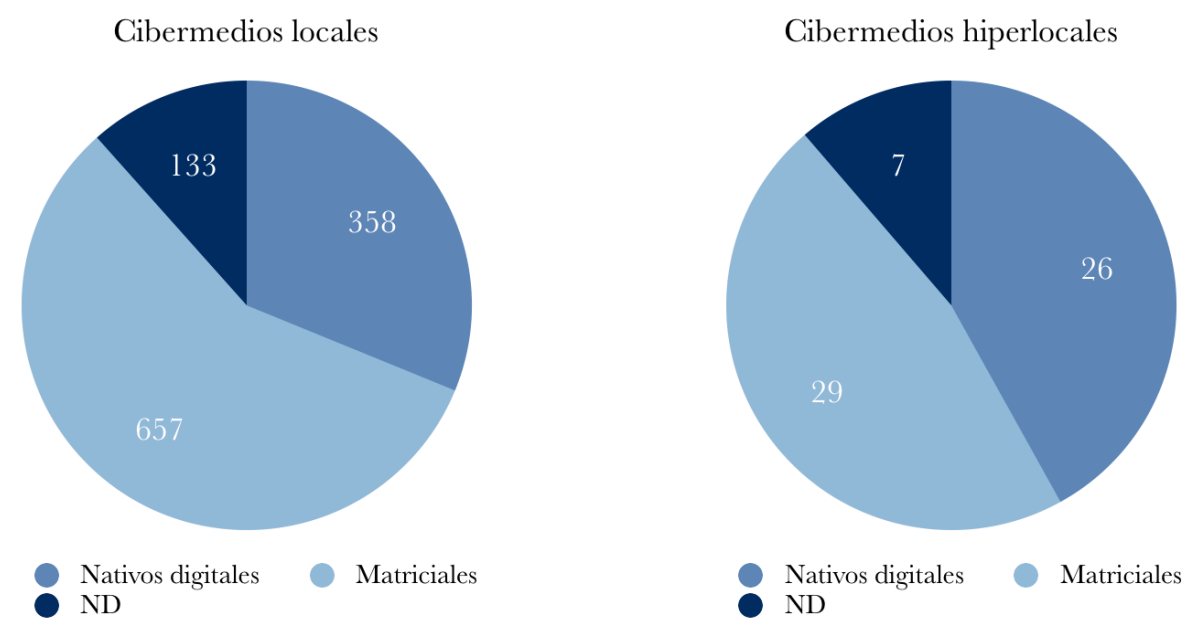

Fuente: elaboración propia.

Aunque el origen matricial de los cibermedios es el más común tanto en los locales como en los hiperlocales, los nativos digitales son más frecuentes entre estos últimos. De forma general, los hiperlocales constituyen el modelo mediático más reciente, caracterizado por unas estructuras organizativas y productivas más reducidas, lo que conlleva unos recursos económicos y humanos más limitados. Todo ello favorece su lanzamiento exclusivo en la red y que tengan dificultades a la hora de expandir su proyecto a otras plataformas. Para algunos autores, el origen nativo digital de los cibermedios hiperlocales llega a ser un elemento definitorio de este tipo de medios. 


\subsubsection{Temporalidad}

Por su concepción de cibermedios, en los que se presupone una producción de contenidos y una actualización constantes, cabría esperar que la totalidad de los locales e hiperlocales estudiados mantuviesen una temporalidad continua. Sin embargo, tal y como se observa en la Figura 4, solo presentan este tiempo de publicación un total de 721 cibermedios locales y 25 hiperlocales.

Aunque predomina la actualización continua de los contenidos, es destacable el mantenimiento de ciclos de publicación periódicos en los cibermedios. Así, hasta 26 cabeceras locales y 11 hiperlocales optan por mantener un mismo intervalo de tiempo entre sus sucesivas ediciones. Con una solución mixta entre ambos modelos, se contabilizan 172 cibermedios locales y 6 hiperlocales con un patrón multitemporal.

Figura 4. Temporalidad de actualización de los cibermedios locales e hiperlocales.
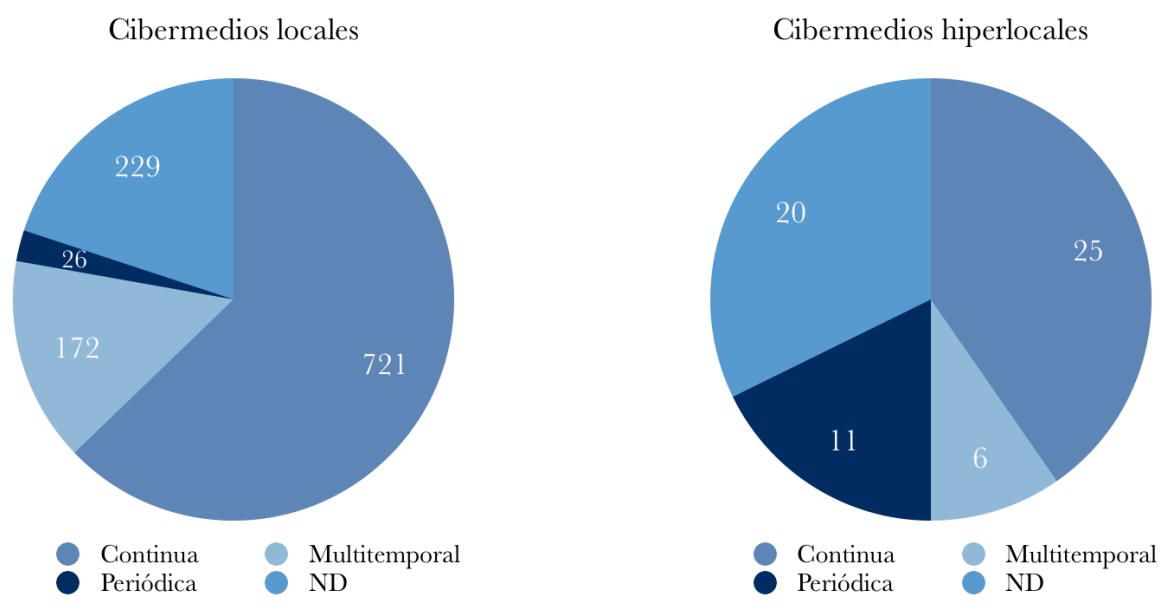

Fuente: elaboración propia.

El hecho de que una parte de los cibermedios locales e hiperlocales opten por mantener un ciclo de publicación más propio de los medios impresos o de radiodifusión puede parecer incoherente. Sin embargo, este comportamiento suele responder a la prioridad editorial que se le da al medio matriz frente al digital, replicando en el segundo los contenidos y tiempos de publicación del primero. En estos casos suele darse, además, una imposibilidad productiva de mantener un ritmo de actualización continuo, produciéndose únicamente publicaciones puntuales no diarias en los cibermedios.

\subsubsection{Titularidad}

La constitución legal y la titularidad empresarial de los cibermedios locales e hiperlocales es una cuestión compleja, pues son muy diversas las formas que han adoptado este tipo de proyectos en los últimos años. En los modelos mediáticos vigentes conviven desde grandes grupos mediáticos privados o corporaciones públicas hasta pequeñas empresas, trabajadores autónomos, cooperativas, asociaciones culturales o gestiones público-privadas de diverso tipo. A esta complejidad hay que sumar una frecuente falta de datos e información corporativa en los sitios web de los cibermedios, lo que ha impedido determinar la titularidad empresarial de 502 cabeceras locales y 27 hiperlocales.

Con todo, tal y como se observa en la Figura 5, los datos revelan una clara predominancia del modelo de propiedad privada, tanto en los cibermedios locales - $(n=574)$ - como en los hiperlocales - $(\mathrm{n}=34)$-. Las cabeceras de titularidad pública son muy poco frecuentes entre los cibermedios locales -solo un 6,3\% del total-, mientras que son excepcionales entre los hiperlocales, registrándose solo una iniciativa de este tipo. 
Figura 5. Titularidad de los cibermedios locales e hiperlocales
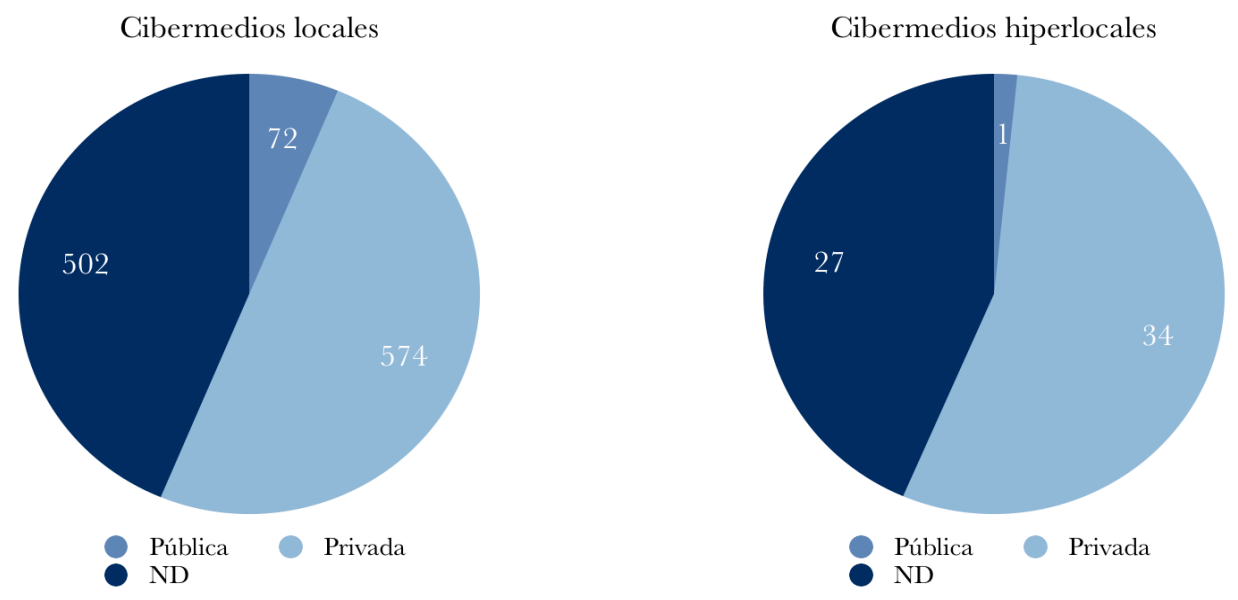

Fuente: elaboración propia.

\subsubsection{Idioma de edición}

En la medida en que los cibermedios locales e hiperlocales se identifican con los rasgos identitarios de la comunidad y la cultura local, resulta relevante el idioma en el que producen y editan sus contenidos. El uso del idioma propio del territorio puede contribuir a reforzar el vínculo que se crea entre el medio y la ciudadanía, favoreciendo que esta se identifique con la cabecera.

Tabla 3. Idiomas de edición de los cibermedios locales e hiperlocales.

\begin{tabular}{|l|c|c|}
\multicolumn{1}{r|}{ Lengua } & Cibermedios locales & Cibermedios hiperlocales \\
\hline Castellano & 765 & 37 \\
\hline Catalán & 315 & 23 \\
\hline Vasco & 49 & 1 \\
\hline Gallego & 48 & 1 \\
\hline Valenciano & 29 & 0 \\
\hline Asturiano & 1 & 0 \\
\hline
\end{tabular}

Fuente: elaboración propia.

Como se observa en la Tabla 3, el castellano es, como idioma oficial del Estado, el que está presente en un mayor número de publicaciones $(n=802)$, representando el $66,6 \%$ de los cibermedios locales y el $59,7 \%$ de los hiperlocales. Le siguen los idiomas cooficiales y oficiales de otras comunidades autónomas, concretamente el catalán $(\mathrm{n}=338)$, el vasco $(\mathrm{n}=50)$, el gallego $(\mathrm{n}=49)$, el valenciano $(n=29)$ y el asturiano $(n=1)$.

La importancia en el uso de las lenguas cooficiales y propias de cada territorio se hace evidente: el número de cibermedios locales en catalán supera a los censados en la propia Cataluña, indicio de que su uso se extiende a otras comunidades de habla catalana, como las Islas Baleares; en el País Vasco hay un 85,9\% de cibermedios locales que tienen edición en vasco; un 56,5\% de los locales de Galicia se publican en gallego; y un 30,5\% de los cibermedios locales de la Comunidad Valenciana lo hacen en valenciano.

Además del importante uso de los idiomas oficiales y cooficiales del Estado, es destacable la edición de algunos cibermedios en otros idiomas extranjeros, como se han localizado en Cataluña, la Comunidad Valenciana, las Islas Baleares o las Canarias. Aquí se contabilizan hasta 8 cabeceras 
editadas en inglés, 4 en alemán y otras 5 en otras lenguas. En estos casos, el uso del idioma sirve para acercar la realidad local a la población extranjera, facilitando así su integración social en el territorio.

\section{Discusión y conclusiones}

En el contexto mediático español se ha constatado un crecimiento relevante en el número de cibermedios activos, llegando a registrarse en el último mapa actualizado un total de 3.065 medios en la red (Salaverría, Martínez-Costa y Breiner, 2018). El mapa elaborado en esta investigación, en el que se localizan e identifican los cibermedios locales e hiperlocales activos, evidencia también una presencia importante de este tipo de medios, con un total de 1.148 locales y 62 hiperlocales.

Si se comparan estos resultados con la primera base de datos de los cibermedios españoles realizada en 2005, en la que se localizaron un total de 1.274 títulos (Salaverría, 2005), se hace evidente el crecimiento de los locales, pues su suma actual casi supera la cifra del total de cibermedios de hace 15 años. Se observa también la entrada de los hiperlocales, un modelo emergente en el plano internacional -como se viene observando en los mapeos realizados en otros países europeos (Harte, 2013; Hujanen et al., 2019; Kerkhoven y Bakker, 2014; Nygren et al., 2018; Halvorsen y Bjerke, 2019) - cuyo auge fue estudiado a partir de los años 2007 y 2008 (Schaffer, 2007). En España, esta etapa coincide también con el inicio de la crisis económica y sus consecuentes efectos adversos en la industria mediática del país.

Estos datos muestran un aumento de los cibermedios fundados con una vocación periodística de proximidad, fruto de un interés y una confianza crecientes en la información y los medios locales (Newman et al., 2020). Se observa, además, una renovación del ecosistema mediático en los ámbitos más próximos a los ciudadanos. Así, en las últimas dos décadas se ha pasado de un escenario dominado por el modelo tradicional de las cabeceras impresas regionales y provinciales, a otro en el que cobran cada vez más presencia los cibermedios que cubren áreas reducidas al mínimo espacio geográfico, administrativo y social.

Constatado el crecimiento de los cibermedios locales e hiperlocales y la presencia creciente de este último modelo emergente, se han conocido también sus características básicas. Estas reflejan un panorama de experimentación y convivencia de modelos diversos, en el que se contraponen la adaptación al escenario digital y la búsqueda de vías para la sostenibilidad económica (Cook, Geels y Bakker, 2016).

De este modo, se observa que a pesar del aumento general de los cibermedios nativos digitales en el mapa español, estos aún no son mayoritarios entre los locales e hiperlocales -condición que, para algunos autores como Metzgar et al. (2011) es definitoria de los medios hiperlocales-. Los resultados señalan que la mayor parte de estos medios presentan una plataforma matricial complementaria a la web, siendo las más frecuentes el papel -que aún resulta rentable en el mercado de los anunciantes y los lectores locales- y la radio - un medio muy extendido a nivel municipal en España-. Se advierte, además, una presencia menor de proyectos televisivos -que conllevan una mayor inversión de capital económico y humano- y una adaptación al medio móvil todavía incipiente con una baja oferta de aplicaciones.

Los limitados recursos económicos y humanos que suelen tener este tipo de proyectos mediáticos reflejan un sector precario -dominado por los medios de titularidad privada- que busca nuevas fuentes de ingresos y modelos rentables de negocio (Salaverría et al., 2019). Esta precariedad puede obstaculizar la adaptación y desarrollo digital de los cibermedios locales e hiperlocales. En el análisis de su temporalidad, se ha observado la pervivencia de ciclos de publicación propios de las cabeceras periódicas, fruto de estrategias en las que la edición digital todavía es secundaria frente a 
la del medio matriz, así como de la imposibilidad de mantener un ritmo de actualización constante en los sitios web.

Con todo, el fuerte vínculo e identificación social que estos medios mantienen con su comunidad local e hiperlocal constituye su activo más valioso. El conocimiento y compromiso con el área local no solo se refleja en su oferta informativa, sino en el idioma empleado para la edición de sus contenidos. Así, los resultados evidencian un uso relevante del catalán, el vasco, el gallego o el valenciano en los cibermedios de Cataluña, el País Vasco, Galicia o la Comunidad Valenciana, respectivamente, haciendo de la lengua propia un elemento más de vinculación y cohesión con la sociedad.

Se concluye, por tanto, que los cibermedios locales e hiperlocales ocupan cada vez más espacio en el panorama mediático español y que sus características están en un proceso de cambio hacia nuevos modelos. El mapa de estos medios servirá como punto de partida para futuras investigaciones, en las que se profundizará en el estudio de casos para el análisis de su producción informativa, relación con la audiencia, formas organizativas y modelos de negocio que van adoptando los cibermedios locales e hiperlocales en España.

\section{Bibliografía}

Ahva, L. y Wiard, V. (2018). Participation in local journalism. Assessing two approaches through access, dialogue and deliberation. Sur le journalisme, 7(2), 64-79. http://www.surlejournalisme. kinghost.net/rev/index.php/slj/article/view/359

Asociación de Emisoras Municipales y Ciudadanas de Andalucía de Radio y Televisión (2020). Asociados por provincias. Asociación de Emisoras Municipales y Ciudadanas de Andalucía de Radio y Televisión. https://www.emartv.es/asociados-por-provincias/\#.XxSFytX-8fE

Asociación de la Prensa de Madrid (2015). Medios lanzados por periodistas. Asociación de la Prensa de Madrid. https://www.apmadrid.es/nuevos-medios-lanzados-por-periodistas/?Itemid=209

Asociación de la Prensa de Madrid (2017). Informe Anual de la Profesión Periodística 2017. Madrid: Asociación de la Prensa de Madrid. https:/www.apmadrid.es/wp-content/ uploads/2018/10/APM-Informe-2017_baja.pdf

Asociación de la Prensa de Madrid (2019). Los medios digitales promovidos por periodistas se afianzan con dificultad. Asociación de la Prensa de Madrid. https://www.apmadrid.es/wp-content/ uploads/2020/03/medios-digitales-promovidos-periodistas-afianzan-dificultad-2019.pdf

Asociación de Medios en Galego (2020). Medios en galego 2020. Asociación de Medios en Galego. https://mediosengalego.gal/100-medios-en-galego/

Associació Catalana de la Premsa Comarcal (2020). Publicacions. Associació Catalana de la Premsa Comarcal. https://www.premsacomarcal.cat/publicacions

Associació de Mitjans d'Informació i Comunicació (2020). Associats. Associació de Mitjans d'Informació i Comunicació. https://www.amic.media/capsaleres/default2.php

Badillo Matos, Á. (2005). Políticas públicas del audiovisual y la desregulación de la televisión local por ondas en España (1980-2004). Sphera publica: revista de ciencias sociales y de la comunicación, 5, 201-228. http://sphera.ucam.edu/index.php/sphera-01/article/view/29/39

Barnett, S. y Townend, J. (2015). Plurality, Policy and the Local. Can hyperlocals fill the gap?. Journalism Practice, 9(3), 332-349. https://doi.org/10.1080/17512786.2014.943930 
Berelson, B. (1952). Content analysis in communication research. Nueva York: Free Press.

Bucay, Y., Elliott, V., Kamin, J. y Park, A. (2017). America's growing news deserts. Columbia Journalism Review. https://www.cjr.org/local_news/american-news-deserts-donuts-local.php

Camponez, C. (2002). Jornalismo de Proximidade. Coimbra: Minerva Coimbra.

Cantalapiedra, M. J. (1997). Periodistas locales. ZER: Revista de Estudios de Comunicación, 2(3).

Chen, N. N., Ognyanova, K., Zhang, C., Wang, C., Ball-Rokeach, S. y Parks, M. (2017). Causing ripples in power relations. The meso-level influence of a hyperlocal news website. Journalism Studies, 18(6), 710-731. http://dx.doi.org/10.1080/1461670X.2015.1078738

COMandalucía (2019a). Mapa de radios públicas locales. Universidad de Málaga. https://comandalucia.org/mapas-interactivos/mapa-radios-publicas-andalucia/

COMandalucía (2019b). Mapa IRSCOM Murcia. Universidad de Málaga. https://com-andalucia. org/mapa-irscom-murcia/

COMandalucía (2017). Radios comunitarias y ciudadanas de Andalucía. Universidad de Málaga. https://com-andalucia.org/radios-comunitarias-y-ciudadanas-de-andalucia/

COMandalucía (2013). Mapa televisiones públicas locales. Universidad de Málaga. https://comandalucia.org/mapas-interactivos/mapa-television-local-publica-en-andalucia/

Cook, C., Geels, K. y Bakker, P. (2016). Hyperlocal Revenues in The UK and Europe. Reino Unido: Nesta.

Dahnke, G. (1986). Investigación y comunicación. En C. Fernández-Collado e G. Dahnke (eds.), La comunicación humana en ciencia social (pp. 385-454). México: McGraw-Hill.

De la Mota, I. H. (1988). Diccionario de la comunicación. Televisión, publicidad, prensa, radio. Madrid: Paraninfo.

D'heer, E. y Paulussen, S. (2013). The Use of Citizen Journalism for Hyperlocal News Production. Recherches en Communication, 39, 151-164. https://biblio.ugent.be/ publication/5833344

Díaz Noci, J. (2005). Historia de los cibermedios en España. En R. Salaverría, (coord.), Cibermedios. El impacto de internet en los medios de comunicación en España (pp. 21-38). Sevilla: Comunicación Social Ediciones y Publicaciones.

Díaz Noci, J. y Meso Ayerdi, K. (1998). Tipología de los medios de comunicación en Internet. Génesis y desarrollo de un nuevo paradigma comunicativo. El caso vasco. XIV Congreso de Estudios Vascos: Sociedad de la Información (pp. 77-83). Donostia : Eusko Ikaskuntza. https://bit. ly/2IcZyZe

Egea Santiago, C. (2002). La carrera por la comunicación local (1998-2000). "Los grandes" se atreven con "lo pequeño". Revista Latina de Comunicación Social, 47. http://www.ull.es/ publicaciones/latina/2002/latina47febrero/4706egea.htm

Esteve Ramírez, F. (2002). La información local como área de especialización periodística. En R. López Lita, F. Fernández Beltrán y A. Durán Mañés (Eds.), La prensa local y la prensa gratuita: I Congreso de Comunicación Local (ComLoc 2001) (pp. 483-491). Castellón de la Plana: Universitat Jaume I, Servei de Comunicació i Publicacions. 
Esteve Ramírez, F. (2012). La información glocal. En J. L. González (coord.), Cuadernos Comarcales de Comunicación. Alto y Medio Vilanolopó (pp. 11-20). Alicante: MediaLab UMH. https://issuu.com/medialabumh/docs/cuadernogicov2

Ferrier M., Sinha G. y Outrich M. (2016). Media Deserts: Monitoring the Changing Media Ecosystem. En M. Lloyd y L. Friedland (Eds.), The Communication Crisis in America, And How to Fix It. New York: Palgrave Macmillan. https://doi.org/10.1057/978-1-349-94925-0_14

Fastrez, P. y Meyer, S. (1999). Télévision locale et proximité. Recherches en communication, 11, 143-167.

Firmstone, J. (2016). Mapping changes in local news. Journalism Practice, 10(7), 928-938. https://doi.org/10.1080/17512786.2016.1165136

Fleischman, L., Reguero, N. y Sáez, C. (2009). Políticas de comunicación y sustentabilidad del tercer sector de la comunicación: el caso catalán en el contexto español y europeo. VII Congreso Internacional de la Unión Latina de Economía Política de la Información, la Comunicación y la Cultura (ULEPICC), 7-9 octubre, Madrid. Recuperado de www.medioscomunitarios.net/ barcelona/IMG/pdf/Ulepicc09_TSC_VF2.pdf

Fleischman, L. y Sáez, C. (2009). Presente y futuro de la sustentabilidad de las experiencias de TV alternativa en España: un análisis multidimensional. Conference of the International Association for Media and Communication Research (IAMCR), 21-24 julio, México. Recuperado de http://amgp.skamp.eu.org/_media/whoswho:f:fleischman_saez_iamcr_final.pdf

Flores Vivar, J. M. (2014). Periodismo hiperlocal, sinergia de dos entornos. Cuadernos de periodistas: revista de la Asociación de la Prensa de Madrid, 29, 38-54. http://www. cuadernosdeperiodistas.com/media/2015/03/38-54-JESUS-FLORES.pdf

Fontcuberta, M. de (1997). La identidad regional de los medios. Cuadernos.info, 12, 44-50. https://doi.org/10.7764/cdi.12.207

Franklin, B. (2006). Local Journalism and Local Media. Making the Local News. Londres: Routlegde. https://doi.org/10.4324/9780203969205

García Avilés, J. A. y González Esteban, J. L. (2012). Cibermedios nativos españoles: explorando modelos de rentabilidad. Trípodos, 30, 153-167. http://www.tripodos.com/index.php/Facultat_ Comunicacio_Blanquerna/article/view/50

González Esteban, J. L. (2009). Modelos de periodismo local y estrategias ante la crisis: el caso del News \& Observer. Revista Latina de Comunicación Social, 12(64), 151-160. http://www. revistalatinacs.org/09/art/14_813_11_MH/latina_art813.pdf

González Esteban, J. L. (2012a). Periodismo hiperlocal y ciberperiodismo de proximidad en las comarcas alicantinas. En J. L. González (coord.), Cuadernos Comarcales de Comunicación. Alto y Medio Vilanolopó (pp. 9-10). Alicante: MediaLab UMH. https://issuu.com/medialabumh/docs/ cuadernogicov2

González Esteban, J. L. (2012b) (coord.). Cuadernos Comarcales de Comunicación. Alto y Medio Vilanolopó. Alicante: MediaLab UMH. https://issuu.com/medialabumh/docs/cuadernogicov2

Guillamet, J. (1983). La premsa comarcal: un model català de periodisme popular. Barcelona: Departament de Cultura de la Generalitat de Catalunya.

Guillamet, J. (2002). Pasado y futuro de la prensa local. En R. López Lita, F. Fernández Beltrán y 
A. Durán Mañés (Eds.), La prensa local y la prensa gratuita (pp. 181-196). Castellón de la Plana: Universitat Jaume I, Servei de Comunicació i Publicacions.

Halvorsen, L. J. y Bjerke, P. (2019). All seats taken? Hyperlocal online media in strong print newspaper surroundings: The case of Norway. Nordicom Review, 40(2), 115-128. https://doi. org/10.2478/nor-2019-0030

Harte, D. (2013). One Every Two Minutes: Assessing the Scale of Hyperlocal. Jomec Journal, 1(3). https://inprogress.cardiffuniversitypress.org/index.php/JOMEC/article/view/309/317

Harcup, T. (2016). Alternative Journalism as Monitorial Citizenship?. Digital Journalism, 4(5), 639-657. https://doi.org/10.1080/21670811.2015.1063077

Harte, D., Turner, J. y Williams, A. (2016). Discourses of Enterprise in Hyperlocal News in the UK. Journalism Practice, 10(2), 233-250. https://doi.org/10.1080/17512786.2015.1123109

Harte, D., Williams, A. y Turner, J. (2016). Reciprocity and the hyperlocal journalist. Journalism Practice, 11, 160-176. https://doi.org/10.1080/17512786.2016.1219963

Hess, K. y Waller, L. (2016). River Flows and Profit Flows: The Powerful Logic Driving Local News. Journalism Studies, 17(3), 263-276. https://doi.org/10.1080/1461670X.2014.981099

Horning, M. A. (2012). In search of hyperlocal news: an examination of the organizational, technological and economic forces that shape 21st century approaches to independent online journalism (Tesis doctoral). The Pennsylvania University, The Graduate School, College of Communications, Pennsylvania,. https://etda.libraries.psu.edu/catalog/13394

Hujanen, J., Lehtisaari, K., Lindén, C. G. y Grönlund, M. (2019). Emerging Forms of Hyperlocal Media. The case of Finland. Nordicom Review, 40(2), 101-114. https://doi.org/10.2478/nor-2019-0029

Izquierdo Labella, L. (2010). Manual de periodismo local. Madrid: Fragua.

Izquierdo Labella, L. (2012). Comunicación glocal: el periodismo local abre una ventana al mundo. Valencia: Tirant Humanidades.

Jenkins, J. y Kleis Nielsen, R. (2018). The Digital Transition of Local News. Oxford: Reuters Institute for the Study of Journalism, University of Oxford. https://reutersinstitute.politics.ox.ac. uk/our-research/digital-transition-local-news

Jenkins, J. y Kleis Nielsen, R. (2020). Preservation and evolution: Local newspapers as ambidextrous organizations. Journalism, 21(4), 472-488. https://doi. org/10.1177/1464884919886421.

Kerkhoven, M. y Bakker, P. (2014). The hyperlocal in practice: Innovation, creativity and diversity. Digital Journalism, 2(3), 296-309. https://doi.org/10.1080/21670811.2014.900236.

Kleis Nielsen, R. (2015). Introduction: The Uncertain Future of Local Journalism. En R. Kleis Nielsen (Ed.), Local Journalism. The Decline of Newspapers and the Rise of Digital Media (pp. 1-25). Londres: I.B. Tauris, Reuters Institute for the Study of Journalism, University of Oxford.

Krippendorf, K. (1980). Content analysis: An introduction to its methodology. California: Sage Publications.

Laboratorio de Periodismo y Comunicación para la Ciudadanía Plural (LPCCP) (2008). Mapa de Medios de Cataluña. Universitat Autònoma de Barcelona. http://labcompublica.info/es/ innovacion/mapa-de-medios-de-cataluna/ 
Lauterer, J. (2006). Community Journalism: Relentlessly Local. Chapel Hill: University of North Carolina Press.

López García, G. (2012). Rasgos generales de los cibermedios de la Comunidad Valenciana. En G. López García (Ed.), Cibercomunidad. El espacio de la comunicación digital en la Comunidad Valenciana (pp. 19-32). Valencia: Tirant lo Blanch.

López García, X. (1999). La información de proximidad en la sociedad global. Revista Latina de Comunicación Social, 13. https://www.ull.es/publicaciones/latina/a1999c/140xose.htm

López García, X. (2004). Desafios de la comunicación local: guía para la práctica de la información en los ámbitos de proximidad. Sevilla: Comunicación Social.

López García, X. (2008). Ciberperiodismo en la proximidad. Sevilla: Comunicación Social.

López García, X., Limia Fernández, M., Isasi Varela, A., Pereira Fariña, X., Gago Mariño, M., Calvo Diéguez, R. y Orihuela, J. L. (2005). Tipología de los cibermedios. En R. Salaverría (coord.), Cibermedios. El impacto de internet en los medios de comunicación en España (pp. 3982). Sevilla: Comunicación Social Ediciones y Publicaciones.

López García, X. y Macià Mercadé, J. (2007). Periodismo de proximidad. Madrid: Editorial Síntesis.

López García, X. y Negreira-Rey, M. C. (2016). La multiplicación de cibermedios hiperlocales y su papel en el ecosistema comunicativo. En Libro de Comunicaciones del V Congreso Iberoamericano de Comunicación "Comunicación, Cultura y Cooperación” (pp. 1726-1746). Madrid: AE-IC.

López de Zuazo, A. (1976). Diccionario del periodismo. Madrid: Pirámide.

Macià Mercadé, J. (1993). La comunicación regional y local: dinámica de la estructura de la información en la España de las autonomías. Madrid: Ciencia 3.

Masip, P. (2008). El ciberperiodismo en Catalunya: apuntes sobre el estado de la cuestión. En G. López García (coord.), Comunicación local y nuevos formatos periodísticos en Internet: cibermedios, confidenciales y weblogs (pp. 35-46). Valencia: Servei de Publicacions de la Universitat de València.

Masip, P., Micó, J. L., Ruiz, C., González, S., Domingo, D. y Nogué, A. (2011). Integración de redacciones en los medios locales y comarcales catalanes. Estudios sobre el Mensaje Periodístico, 17(1), 167-182. http://dx.doi.org/10.5209/rev_ESMP.201.v17.n1.9

Martínez Juan, A. (2003). Los retos del periodismo local en la red: hacia una definición del espacio local en la Era global. Sala de Prensa, 59.

Metzgar, E., Kurpius, D. y Rowley, K. (2011). Defining hyperlocal media: Proposing a framework for discussion. New Media \& Society, 13(5), 772-787. https://doi.org/10.1177/1461444810385095

McLuhan, M. y Powers, B. R. (1992). The Global Village: Transformations in World Life and Media in the 21st Century. Oxford: Oxford University Press.

Moragas, M. de (2015). La comunicación de proximidad 30 años después. En A. Nerekan Umaran, M. Á. Casado del Río, R. Zallo Elgezabal y J. C. Miguel de Bustos (eds.), Comunicación de proximidad: cada vez más lejos. Marco, experiencias y regulación (pp. 21-38). Bilbao:

Universidad del País Vasco. 
Moragas, M. de, Garitaonandía, C. y López, B. (1999). Televisión de proximidad en Europa. Experiencias de descentralización en la era digital. Bellaterra; Castelló de la Plana; Barcelona; València: Universitat Autònoma de Barcelona; Publicacions de la Universitat Jaume I; Universitat Pompeu Fabra; Universitat de València.

Negreira-Rey, M. C. (2017). Mediamapa.gal: mapear, investigar y divulgar la realidad mediática de Galicia a través de un proyecto abierto en la red. En A. De Lara González y F. Arias Robles (eds.), Mediamorfosis. Perspectivas sobre la innovación en periodismo (pp. 118-129). Elche, Alicante: Universidad Miguel Hernández. http://editorial.umh.es/2017/11/27/mediamorfosisperspectivas-sobre-la-innovacion-en-periodismo-2/

Negreira-Rey, M. C., López-García, X. y Rodríguez-Vázquez, A. I. (2018). Los cibermedios locales e hiperlocales en España y Portugal. La fase de búsqueda de modelos. Sur le journalisme, 7(2), 50-63. http://www.surlejournalisme.kinghost.net/rev/index.php/slj/article/ view/358

Newman, N., Fletcher, R., Shulz, A., Andi, S. y Kleis, R. (2020). Digital News Report 2020. Oxford: Reuters Institute for the Study of Journalism. https://reutersinstitute.politics.ox.ac.uk/ sites/default/files/2020-06/DNR_2020_FINAL.pdf

Nygren, G., Leckner, S. y Tenor, C. (2018). Hyperlocals and Legacy Media. Media Ecologies in Transition. Nordicom Review, 39(1), 33-49. https://doi.org/10.1515/nor-2017-0419

Pereira, J., Gago-Mariño, M., López, X., Salaverría-Aliaga, R., Díaz-Noci, J., Meso-Ayerdi, K., Cabrera, M. Á. y Palomo, M. B. (2005). El impacto de internet en los medios de comunicación en España. Aproximación metodológica y primeros resultados. En A. Fidalgo y P. Serra (Org.), Actas dos III Sopcom, IV Lusocom e II Ibérico (pp. 361-369). Portugal: Servicios Gráficos da Universidade da Beira Interior.

Pérez Dasilva, J. A. y Santos Díez, T. (2009). Las televisiones locales del País Vasco en Internet. Revista Latina de Comunicación Social, 64, 192-202. www.revistalatinacs.org/09/art/17_816_18_ Bilbao/Perez_Dasilva_y_Santos_Diez.html

Radcliffe, D. (2012). Here and Now: UK hyperlocal media today. Reino Unido: Nesta. https:// www.nesta.org.uk/report/here-and-now-uk-hyperlocal-media-today/

Radcliffe, D. (2015). Where are we now? UK hyperlocal media and community journalism in 2015. United Kingdom: Nesta, Centre for Community Journalism (Cardiff University). https:// papers.ssrn.com/sol3/papers.cfm?abstract_id=3045571

Richards, I. (2013). Beyond city limits: Regional journalism and social capital. Journalism, 14(5), 627-642. https://doi.org/10.1177/1464884912453280

Ruiz del Árbol, A. (1986). Prensa cercana. Alfoz, diciembre de 1986. Madrid.

Salaverría, R. (2008). Ciberperiodismo. Diez años de prensa digital en España. En J. J. Fernández Sanz (ed.), Prensa especializada. Doce calas (pp. 355-383). Madrid: McGraw-Hill.

Salaverría, R. (2017). Tipología de los cibermedios periodísticos: bases teóricas para su clasificación. Revista Mediterránea de Comunicación/Mediterranean Journal of Communication, 8 (1), 19-32. https://www.doi.org/10.14198/MEDCOM2017.8.1.2

Salaverría, R., Cores, R., Díaz Noci, J., Meso, K. y Larrondo, A. (2004). Evaluación de los ciberdiarios en las comunidades vasca y navarra. Comunicación y Sociedad, 17(1), 161-189. https://hdl.handle.net/10171/8108 
Salaverría, R., Martínez-Costa, M. P. y Breiner, J. (2018). Mapa de los cibermedios de España en 2018: análisis cuantitativo. Revista Latina de Comunicación Social, 73, 1034-1053. https://doi. org/10.4185/RLCS-2018-1295

Salaverría, R., Martínez-Costa, M. P., Breiner, J., Negredo, S., Negreira, M. C. y Jimeno, M. A. (2019). El mapa de los cibermedios en España. En C. Toural y X. López (eds.), Ecosistema de cibermedios en España. Tipologías, iniciativas, tendencias narrativas y desafios (pp. 25 - 49). Salamanca: Comunicación Social Ediciones y Publicaciones.

Schaffer, J. (2007). Citizen Media: Fad Or the Future of News?: the Rise and Prospects of Hyperlocal Journalism. J-Lab, The Institute for Interactive Journalism. http://www.j-lab.org/ publications/citizen-media/

Schmitz Weiss, A. (2020), Journalists and Their Perceptions of Location: Making Meaning in the Community. Journalism Studies, 21(3), 352-369. https://doi.org/10.1080/1461670X.2019.1664315

Schmitz Weiss, A. (2015). Place-Based Knowledge in the Twenty-First Century. Digital Journalism, 3(1), 116-131. https://doi.org/10.1080/21670811.2014.928107

Tenor, C. (2019). Logic of an effectuating hyperlocal: Entrepreneurial processes and passions of online news start-ups. Nordicom Review, 40(2), 129-145. https://doi.org/10.2478/nor-2019-0031

Tokikom (2020). Medios asociados. Toki komunikabideen bateragunea Euskara. https://tokikom. eus/medios-asociados/

Wadbring, I. y Bergström, A. (2017). A Print Crisis or a Local Crisis?. Journalism Studies, 18(2), 175-190, https://doi.org/10.1080/1461670X.2015.1042988

Williams, A., Harte, D. y Turner, J. (2015). The Value of UK Hyperlocal Community News: Findings from a content analysis, an online survey and interviews with producers. Digital Journalism, 5, 680-703. https://doi.org/10.1080/21670811.2014.965932 